\title{
Colaboração para o Desenvolvimento de Dashboards de Business Intelligence
}

\author{
Rodrigo Oliveira ${ }^{1}$ \\ ${ }^{1}$ Universidade Federal do Rio de Janeiro (UFRJ) \\ Programa de Pós-Graduação em Informática (PPGI) \\ Cidade Universitária - Ilha do Fundão \\ Rio de Janeiro - RJ - Brazil \\ rodrigo.oliveiralppgi.ufrj.br
}

\begin{abstract}
Visualizations assist in decision making in the Business Intelligence (BI) area as they bring understanding about data in the form of dashboards. However, developers of such resources now deal even more with a distributed creative landscape that requires more collaboration stemming from the COVID-19 pandemic. The tools available on the market offer few features that support this need for work amplified by social distance. This article reports the planning of a research that aims to bring together the experiences of teams creating BI panels that work remotely, thus contributing with suggestions for improving the software that supports this performance.
\end{abstract}

Resumo. Visualizações auxiliam na tomada de decisões na área de Business Intelligence (BI) na medida que trazem entendimento sobre os dados no formato de dashboards. Todavia os desenvolvedores de tais recursos agora lidam ainda mais com um cenário criativo distribuído que requer mais colaboração advindo da pandemia de COVID-19. As ferramentas disponíveis no mercado oferecem poucas funcionalidades que apoiam essa necessidade de trabalho amplificado pelo distanciamento social. $O$ presente artigo relata o planejamento de uma pesquisa que visa reunir as experiências das equipes de criação de dashboards para BI que atuam de forma remota, contribuindo assim com sugestões de melhoria dos softwares que apoiem essa performance.

\section{Introdução}

Visualização ${ }^{1}$ é o ato ou efeito de visualizar, tornar algo visual ou visível. Aproximando esse conceito da Ciência da Computação temos o sentido de que a visualização usa dados que não são visuais e os mapeia para um domínio visual (Manovich, 2011). Altera o processo cognitivo de lógico e linguístico, quando lemos palavras ou números em uma tabela, para uma percepção instantânea quando vemos um gráfico (Dix, 2012). A colaboração se une a essa área permitindo a mais de um usuário contribuir no processo de desenvolvimento de algum recurso. Segundo Isenberg et al. (2011) a chamada visualização colaborativa é o uso compartilhado de representações visuais de dados (interativas) suportadas por computador por mais de uma pessoa com o objetivo comum de contribuir para atividades conjuntas de processamento de informações.

\footnotetext{
${ }^{1}$ https://michaelis.uol.com.br/moderno-portugues/busca/portugues-brasileiro/visualização/
} 
Através da matriz espaço tempo apresentada por Filippo et al. (2007) na Figura 1, podemos distinguir as diferentes configurações que podem se apresentar neste cenário.

\begin{tabular}{|c|c|c|}
\hline & $\begin{array}{l}\text { mesmo tempo } \\
\text { (síncrono) }\end{array}$ & $\begin{array}{l}\text { tempo diferente } \\
\text { (assíncrono) }\end{array}$ \\
\hline $\begin{array}{l}\text { mesmo lugar } \\
\text { (local) }\end{array}$ & $\begin{array}{c}\text { Interações síncronas } \\
\text { face-a-face } \\
\text { Brainstorming }\end{array}$ & $\begin{array}{c}\text { Interações assíncronas } \\
\text { locais } \\
\text { Post-It Notes }\end{array}$ \\
\hline $\begin{array}{l}\text { ESPAÇO } \\
\text { local diferente } \\
\text { (distribuído) }\end{array}$ & $\begin{array}{c}\text { Interações síncronas } \\
\text { distribuídas } \\
\text { Bate-papo } \\
\text { Videoconferência }\end{array}$ & $\begin{array}{c}\text { Interações assíncronas } \\
\text { distribuídas } \\
\text { Correio eletrônico } \\
\text { Fórum }\end{array}$ \\
\hline
\end{tabular}

Figura 1. Matriz Espaço-Tempo para Sistemas Colaborativos. Fonte: Filippo et al. (2007)

A interseção dessas áreas de conhecimento resulta em desafios próprios como: i) inserção de mais usuários com diferentes atribuições no processo de criação das visualizações; ii) suporte ao entendimento de cada indivíduo e suas interações com o grupo para a análise e interpretação dessas visualizações; iii) melhoria das representações visuais, com cada usuário realizando suas operações simultaneamente, sendo necessário uma gestão de conflitos, versionamento e etc. $\mathrm{O}$ foco deste artigo é a colaboração envolvida nos grupos que criam visualizações (designers e/ou desenvolvedores), no contexto específico de inclusão em dashboards ou painéis. Segundo Few (2006) esse é um formato recorrente para apresentação visual das informações mais importantes organizadas em uma única tela, visando uma monitoração rápida e apoio a tomada de decisão de terceiros, como uma parte do processo de Business Intelligence $(\mathrm{BI})$.

É inegável que a pandemia gerada pelo novo coronavírus torna esse tópico mais relevante. O chamado "novo normal" obrigou o distanciamento como medida preventiva ao contágio. Diversas equipes de desenvolvimento se viram obrigadas a atuar integralmente de forma remota, sofrendo inúmeras adaptações para o trabalho colaborativo. Nossa motivação para este estudo advém dos poucos recursos associados à colaboração disponíveis nas ferramentas mais comuns de desenvolvimento de visualizações do mercado. Dentre os softwares mais utilizados listados pela empresa de telecomunicações Leucotron ${ }^{2}$ e Mindminers ${ }^{3}$ de pesquisas digitais, a maioria se limita a oferecer apenas o compartilhamento de seus painéis ou visualizações entre usuários. Esse resultado foi obtido através de uma análise exploratória preliminar das funcionalidades que estes softwares divulgam em suas páginas web de produtos. $\mathrm{Na}$ Tabela 1 temos os links da busca de cada ferramenta e sua pontuação com o valor 1 caso apresente a função associada à colaboração ou 0 quando não há descrição sobre tal função. Reforçamos com esse resultado a hipótese de que tais ferramentas são minimamente voltadas ao tópico da colaboração e, não embarcam soluções que poderiam melhorar a performance das equipes colaborativamente distribuídas.

\footnotetext{
${ }^{2}$ https://blog.leucotron.com.br/visualizacao-de-dados/

${ }^{3}$ https://mindminers.com/blog/ferramentas-de-bi/
} 
Tabela 1. Pontuação dos softwares de visualização para funcionalidades de colaboração.

\begin{tabular}{lccccccc} 
Software & $\begin{array}{c}\text { Base } \\
\text { compartilhada }\end{array}$ & $\begin{array}{c}\text { Múltiplos } \\
\text { Usuários }\end{array}$ & $\begin{array}{c}\text { Alterações } \\
\text { simultâneas }\end{array}$ & $\begin{array}{c}\text { Permissões } \\
\text { variadas }\end{array}$ & $\begin{array}{c}\text { Comunicação } \\
\text { dos usuários }\end{array}$ & $\begin{array}{c}\text { Outras } \\
\text { funções }\end{array}$ & Total \\
\hline$\underline{\text { Tableau }}$ & 1 & 0 & 0 & 0 & 0 & 0 & 1 \\
\hline$\underline{\text { Google Data }}$ & 1 & 1 & 1 & 0 & 0 & 0 & 3 \\
$\underline{\text { Ptudio }}$ & 1 & 1 & 0 & 0 & 0 & 0 & 2 \\
\hline$\underline{\text { IBM Watson BI }}$ & 1 & 0 & 0 & 0 & 0 & 0 & 1 \\
\hline$\underline{\text { QlikView }}$ & 1 & 0 & 0 & 0 & 0 & 0 & 1 \\
\hline Microstrategy & 1 & 0 & 0 & 0 & 0 & 0 & 1 \\
\hline
\end{tabular}

Com esse cenário buscamos responder às seguintes perguntas de pesquisa:

- Quais as principais práticas (facilidades e dificuldades) dos designers para desenvolver dashboards durante o trabalho remoto frente aos recursos disponíveis dos softwares que utiliza?

- Quais funcionalidades podem ser adicionadas às ferramentas de visualização que suportem as necessidades de colaboração das equipes e melhore sua performance na criação de visualizações?

Nosso objetivo principal é identificar os principais pontos de melhoria para as ferramentas de criação de visualizações para dashboards. O presente trabalho está estruturado em seções e, além desta introdução, conta com uma revisão dos trabalhos relacionados ao tema proposto na Seção 2. Na Seção 3 apresenta uma breve descrição da metodologia a ser utilizada e os detalhes já elaborados em um plano de pesquisa.

\section{Trabalhos Relacionados}

Losev et al. 2020 apresenta as experiências de formação e adaptação de uma equipe de design de visualização atuando de forma distribuída e síncrona durante a pandemia de COVID-19. Com uma abordagem autoetnográfica os autores refletem sobre os desafios impostos no cenário atual como: coordenar o tempo e o acesso ao espaço virtual, determinar o progresso dos indivíduos na equipe, variação nos níveis de habilidade dos membros e compreensão da perspectiva do outro no processo de criação.

Estes desafios geraram soluções de adaptação no uso dos softwares na tentativa de criar uma colaboração em tempo real através de esboços, como: a experiência do compartilhamento de tela usando vídeo chamadas e o uso de gestos manuais para discussão das interações. Enquanto essa abordagem se aprofunda na nova experiência da equipe e nos recursos que apararam as interações do grupo, este artigo se distingue ao propor a coleta das mesmas experiências porém com o propósito de contribuir com novas funções aos próprios softwares de visualização. 
O trabalho de Neogy et al 2020 contudo é uma referência de funcionalidade que pode ser integrada aos softwares e melhorar o desenvolvimento das equipes de visualização em geral. A pesquisa desenvolve uma representação da colaboração multiusuário síncrona traduzida em cursores interativos em cada visualização. Diversos usuários exploram e analisam interativamente a mesma visualização em vários locais e dispositivos. Interagindo com essas representações ou conferindo a visão de um outro colaborador, rastreando e acompanhando em tempo real. Todavia o foco dos autores é nos processos de análise em vez de ser no processo de design que é a proposta desta pesquisa e diferença entre os trabalhos. Ainda que a proposta relacionada possa ser uma contribuição de nova funcionalidade também para designers e desenvolvedores.

\section{Metodologia e Plano de Pesquisa}

Através da metodologia de estudo de caso (Yin, 2015) e uma coleta de dados com um questionário exploratório (Wohlin et al., 2012) algumas etapas já foram definidas conforme a Figura 3. Inicialmente os objetivos e perguntas de pesquisa já foram descritos nas seções anteriores. O questionário como instrumento da pesquisa será composto de perguntas abertas para capturar detalhes e enriquecer a coleta de dados que permitam responder às questões de pesquisa. O questionário será conduzido de forma online ou quando necessário com a participação presencial.

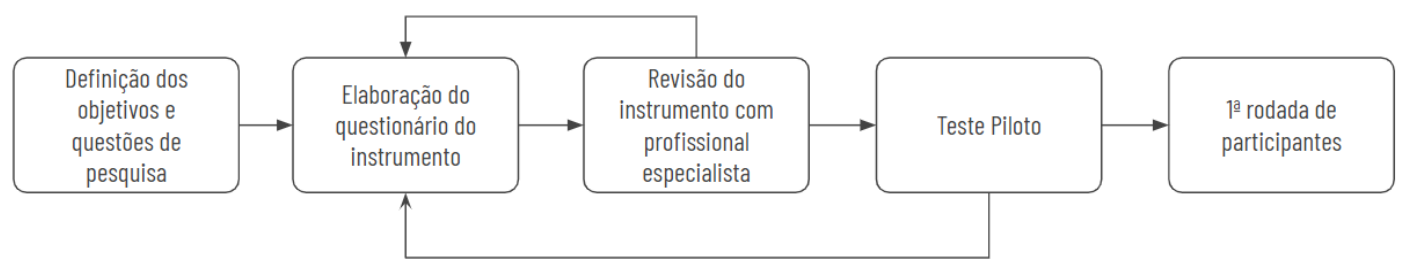

Figura 3. Etapas de elaboração do questionário para coleta de dados. Fonte: o autor.

Uma revisão da primeira versão do questionário será realizada em uma seção online com um especialista ou gestor de projetos da área de desenvolvimento de visualizações para validar a interpretabilidade das questões e as respostas captadas. Após a implementação das alterações sugeridas, um teste piloto será executado com um participante que integre um grupo de desenvolvedores para comprovar a adequação das perguntas e a forma de condução do estudo. As perguntas do questionário estão em elaboração, sendo algumas já propostas como:

- O que mais dificulta as suas atividades individuais no trabalho remoto para criação de alguma visualização?

- O que mais facilita as suas atividades individuais no trabalho remoto para criação de alguma visualização?

- O que mais dificulta as suas atividades em grupo em trabalho remoto para criação de alguma visualização?

- O que mais facilita as suas atividades em grupo em trabalho remoto para criação de alguma visualização?

- Qual software é utilizado para criar as visualizações em seu grupo? 
- Quais as funcionalidades são oferecidas para possibilitar a colaboração em grupo?

- Quais funcionalidades ele deveria oferecer que melhorariam a performance do trabalho em grupo?

- Qual ferramenta as equipes utilizam para comunicação entre si?

- Qual ferramenta as equipes utilizam para organizar as tarefas entre si?

Além das perguntas para identificar o perfil do participante, como o tamanho do grupo que ele pertence, sua experiência na área e formação acadêmica. Os participantes serão integrantes de 5 pequenas equipes de desenvolvedores de visualização com 3 a 5 integrantes cada de uma startup de saúde associada a uma universidade brasileira mas espalhados pelos estados do Brasil. Através da rede de contatos destes profissionais poderão ser alcançadas novas equipes a serem incluídas na pesquisa. Ao final da coleta dos dados uma análise de sistematização e codificação das respostas será realizada para apresentar os resultados e as contribuições da pesquisa.

\section{Referências}

Manovich, L. (2011). What is visualisation?. Visual Studies, 26(1), 36-49.

Dix, A. (2012, January). Introduction to information visualisation. In PROMISE Winter School (pp. 1-27). Springer, Berlin, Heidelberg.

Filippo, D., Raposo, A., Endler, M., \& Fuks, H. (2007). Ambientes colaborativos de realidade virtual e aumentada. C. Kirner, R. Siscoutto, EDS, 168-191.

Few, Stephen. (2006). Information dashboard design: The effective visual communication of data. O'Reilly Media, Inc.

Losev, T., Storteboom, S., Carpendale, S., \& Knudsen, S. (2020). Distributed Synchronous Visualization Design: Challenges and Strategies. arXiv preprint arXiv:2009.02306.

Neogy, R., Zong, J., \& Satyanarayan, A. (2020). Representing Real-Time Multi-User Collaboration in Visualizations. arXiv preprint arXiv:2009.02587.

Wohlin, C., Runeson, P., Höst, M., Ohlsson, M. C., Regnell, B., \& Wesslén, A. (2012). Experimentation in software engineering. Springer Science \& Business Media.

Yin, R. K. (2015). Estudo de Caso-: Planejamento e métodos. Bookman editora. 